\title{
RESPON OVARIUM SAPI LIMOUSIN DAN SIMMENTAL TERHADAP INDUKSI FOLLICLE STIMULATING HORMONE
}

\author{
Sukardi Liamanu, Lentji Rinny Ngangi*, Santie H Turangan, Jouke. H. Manopo
}

Fakultas Peternakan Universitas Sam Ratulangi Manado

\begin{abstract}
ABSTRAK
Untuk mengkaji pengaruh pemberian FSH terhadap tingkat respon ovarium. Dan Untuk mengkaji pengaruh sinkronisasi gelombang folikel terhadap tingkat respon ovarium dan perolehan embrio yang layak transfer.

Penelitian ini telah dilaksanakan di Laboratorium Produksi embrio Balai Embrio Ternak Cipelang kecamatan Cijeruk kabupaten Bogor, selama 30 hari. Materi yang digunakan dalam penilitian ini adalah 50 ekor ternak sapi yang terdiri dari 25 ekor sapi betina Limousin dan 25 ekor sapi betina Simmental berumur sekitar 5-7 tahun, pernah beranak, rata-rata telah pernah dilakukan superovulasi, nilai BCS 2,5-3.0, sehat dan diberikan pakan hijauan dan konsentrat (Protokol BET). FSH yang digunakan dalam superovulasi merek Folltropin $^{\circledR}$-V dengan dosis $20 \mathrm{mg} / \mathrm{ml}$, Semen yang digunakan sesuai dengan jenis sapi donor, dengan kosentrasi $25 \times 10^{6}$ spermatozoa per straw

Pengambilan data primer dilakukan dengan metode observasi teknik focal animal sampling yang mengharuskan pengamatan langsung dilokasi penelitian dimana materi penelitian berada. Variabel yang diukur adalah response rate, jumlah CL pada ovarium kiri dan kanan, total embrio dan ovum yang terkoleksi,

Superovulasi dengan mengunakan Folltropin ${ }^{\circledR}-V$ pada sapi Simmental dan Limousin Balai Embrio Ternak Cipelang memberikan pengaruh yang nyata lebih
\end{abstract}

*Korespondensi (corresponding author): Email: lentjingangi@gmail.com banyak pada sapi Simmental dibandingkan dengan sapi Limousin. Sapi Limousin dan Simmental yang disuperovulasi dengan hormon Folltropin ${ }^{\circledR}-\mathrm{V}$ menghasilkan rataan jumlah CL, embrio dan ovum pada sapi Simmental lebih tinggi dari pada sapi Limousin disuperovulasi dengan hormon FSH. berpengaruh nyata terhadap nilai response rate, recovery rate, rataan jumlah CL dan rataan jumlah embrio. Hasil penelitian yang diperoleh menunjukkan bahwa perbedaan bangsa sapi Limousin dan Simmental berpengaruh nyata terhadap jumlah embrio dan ovum terkoleksi, proporsi embrio layak transfer, proporsi embrio Degenerate (Dg) dan proporsi Embrio Unfertilized (UF) yang tidak terbuahi.

Kata Kunci : Sapi Limousin, Sapi Simmental, Superovulasi, FSH

\section{ABSTRACT}

OVARIUM RESPONSE OF LIMOUSIN COWS AND SIMMENTAL COWS ON FOLLICLE STIMULATING HORMONE INDUCTION. To assess the effect of $\mathrm{FSH}$ administration on ovarian response rates. and to examine the effect of synchronizing follicular waves on ovarian response rates and the acquisition of embryos that are worthy of transfer.

This research was carried out at the Laboratory of Embryo Production of Livestock Embryo Hall Cipelang Cijeruk district, Bogor regency, for 30 days. The materials used in this research were 50 cattle consisting of 25 female Limousin 
cows and 25 Simmental female cows at the aged around 5-7 years. They have given birth, and have been superovulated, at the body condition score (BCS) of 2.5-3.0, at the healthy and given forage and concentrate (BET protocol). FSH used was the Folltropin ${ }^{\circledR}-\mathrm{V}$ brand superovulation with a dose of $20 \mathrm{mg} / \mathrm{ml}$, the cement used was in accordance with the type of donor cow, with a concentration of $25 \times 106$ spermatozoa per straw

Primary data retrieval were done by observing the focal animal sampling technique requiring direct observation in the research location where the research material was located. The variables measured were response rate, number of corpus luteum (CL) in the left and right ovaries, the total collected embryos and ovum.

Superovulation using Folltropin ${ }^{\circledR}$ $\mathrm{V}$ in Simmental and Limousin cattle at Cipelang Livestock Embryo gave more significantly effect on Simmental cattle compared to Limousin cattle. Limousin and Simmental cattle supplemented with the hormone Folltropin ${ }^{\circledR}-\mathrm{V}$ produced an average number of CL, embryos and ovum in Simmental cattle higher than Limousin cattle superovulated with FSH hormone. They have also a significant effect on the response rate, recovery rate, average CL number and the average number of embryos. The results obtained showed that Limousin and Simmental cattle differences significantly affected the number of collected embryos and ovum, the proportion of transferable embryos, Degenerate $(\mathrm{Dg})$ embryo proportions and unfertilized proportion of Embryo Unfertilized (UF).

\section{PENDAHULUAN}

Penerapan teknologi pada bidang peternakan adalah upaya untuk meningkatkan manajemen peternakan, terutama pada reproduksi ternak sapi. Transfer embrio (TE) merupakan aplikasi bioteknologi reproduksi generasi II yang dikenal di Indonesia setelah inseminasi buatan (IB). TE merupakan suatu sistem perkawinan yang memproduksi banyak embrio dalam satu siklus estrus dan ditransfer ke resipien sampai lahir diharapkan dapat memberikan sumbangsih dalam upaya peningkatan populasi dan genetik sapi, walaupun secara nasional masih perlu dibenahi dan masih perlu adanya penelitian-penelitian untuk penyempurnaan. Fortune (1994) Efisiensi reproduksi sapi betina sangat rendah bila ditinjau dari aspek jumlah ova yang diovulasikan yang biasanya hanya satu per siklus estrus (monotokus) dan aspek potensi oosit yang dimilikinya. Potensi oosit sapi betina sebanyak puluhan ribu dianggap mubasir, karena secara alamiah sapi betina selama usia produktifnya atau selama hidupnya hanya dapat memproduksi anak sebanyak 6-8 ekor. Toelihere (1985) menyatakan bahwa dalam ovarium sapi betina normal terdapat 140.000 oosit sampai sapi berumur empat sampai enam tahun dan kemudian jumlahnya menurun sampai 25.000 pada umur 10-14 tahun dan 
mendekati nol pada umur 20 tahun. Teknologi TE yang didalamnya mencakup teknologi reproduksi superovulasi dapat digunakan untuk mengoptimalkan potensi oosit yang dimiliki oleh sapi induk donor. Gordon (2003) Pelaksanaan superovulasi dalam rangkaian proses TE bertujuan untuk meningkatkan jumlah oosit yang diovulasikan oleh betina donor yang mengalami perlakuan untuk nantinya ditransferkan kebetina resipien dengan kemungkinan tinggi menjadi bunting.

Salah satu masalah utama dalam program transfer embrio adalah tingginya variabilitas respon terhadap superovulasi pada induk donor. Banyak ditemui induk donor yang mengalami kegagalan ovulasi (anovulation) dari beberapa folikel dominan. Dalam kegiatan superovulasi, penggunaan hormon gonadotropin eksogen berfungsi untuk meningkatkan stimulasi pertumbuhan folikel. Waktu optimal aplikasi gonadotropin akan memberikan hasil yang maksimal, efisiensi waktu, tenaga, biaya dan penggunaan donor. Diharapkan dengan adanya induksi hormon gonadotropin kepada sapi donor akan meningkatkan jumlah folikel primordial yang berkembang menjadi folikel dominan dan seterusnya menjadi folikel de Graff dalam jangka waktu yang hampir bersamaan.

Berdasarkan permasalahan dan kerangka pemikiran diatas, maka akan dilakukan penelitian dengan judul "Respon Ovarium Sapi Eksotik Limousin dan Simmental Terhadap Induksi Follicle Stimulating Hormone".

\section{MATERI DAN METODE PENELITIAN}

\section{Lokasi dan Waktu Penelitian}

Penelitian ini telah dilaksanakan di Laboratorium Produksi embrio Balai Embrio Ternak Cipelang Kecamatan Cijeruk Kabupaten Bogor selama 30 hari.

\section{Materi Penelitian}

Materi yang digunakan dalam penilitian ini adalah 50 ekor ternak sapi yang terdiri dari 25 ekor sapi betina Limousin dan 25 ekor sapi betina Simmental berumur sekitar 5-7 tahun, pernah beranak, rata-rata telah pernah dilakukan superovulasi, nilai BCS 2,5 -3.0, sehat dan diberikan pakan hijauan dan konsentrat (Protokol BET). FSH yang digunakan dalam superovulasi merek Folltropin ${ }^{\circledR}-\mathrm{V}$ yang diproduksi Bioniche Animal Health Pty Ltd Australia dengan dosis $20 \mathrm{mg} / \mathrm{ml}$ Semen yang digunakan sesuai dengan jenis sapi donor, dengan kosentrasi $25 \times 10^{6}$ spermatozoa per straw.

\section{Metode Penelitian}

Pengambilan data primer dilakukan dengan metode observasi teknik focal 
animal sampling yang mengharuskan pengamatan langsung dilokasi penelitian dimana materi penelitian berada (Yamin et al., 2014).

\section{Prosedur penelitian}

\section{Superovulasi}

Produksi embrio dilakukan secara in vivo, sapi betina donor diinduksi superovulasi dengan dua kali penyuntikan hormon gonadotropin FSH per hari (pagi dan sore) secara intra muscular pada hari ke 9 sampai hari ke 12 setelah estrus. Injeksi FSH dilakukan secara berulang 8 kali selama 4 hari dengan dosis menurun 20 $(4,4,3,3,2,2,1,1) \mathrm{mg}$ FSH. Interval waktu antara injeksi siang dan sore 7-8 jam (Protokol BET Cipelang) (Mapletof dan Bố 2012).

\section{Induksi estrus}

Hari ketiga setelah skedul (Protokol BET Cipelang) betina donor diberikan $\mathrm{PGF}_{2}$ alfa yang berfungsi meregresikan CL dan menginduksi estrus, sehingga 2-3 hari setelah perlakuan diharapkan sapi akan estrus.

\section{Inseminasi donor yang telah disuperovulasi}

Inseminasi donor dilakukan 10-24 jam (protokol BET Cipelang) setelah estrus pertama kali muncul atau pada siang hari pada hari kelima pelaksanaan superovulasi dan inseminasi kedua pagi hari pada hari keenam pelaksanaan superovulasi.

\section{Pemanenan embrio (flushing)}

Koleksi embrio dengan cara non operasi (non surgical) menggunakan kateter Foley yang dimasukan kedalam cornua uterus, dilakukan pada hari ke 7 setelah inseminasi pertama (hari ke 20) setelah estrus. Uraian lengkap untuk alur proses superovulasi dan jadwal pemberian perlakuan penelitian disajikan dalam gambar (4) dan bagan alur proses superovulasi.

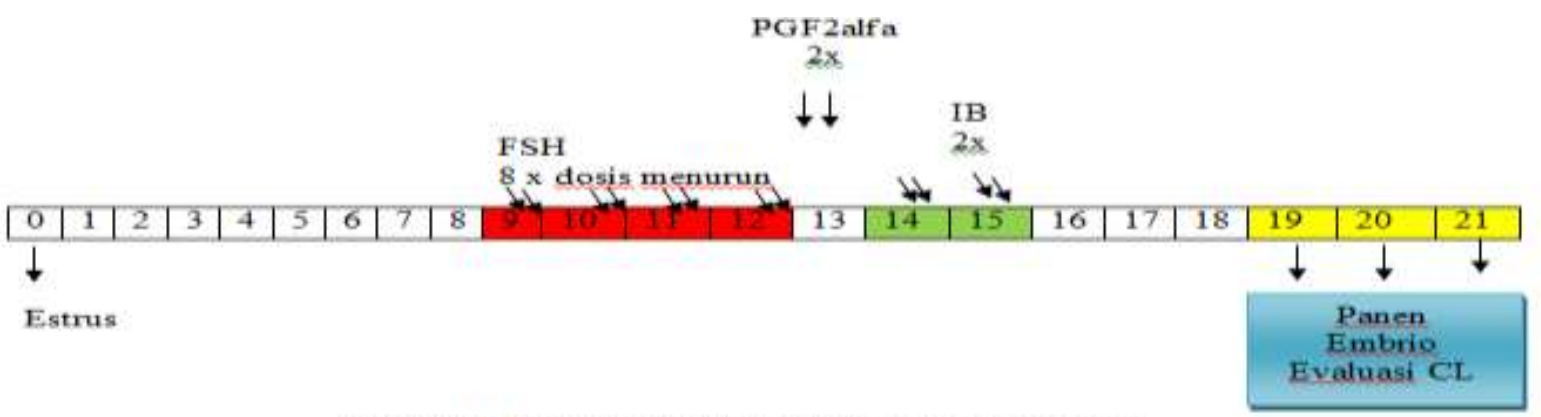




\section{Analisa Data}

Data diolah secara deskriptif dan disajikan dalam bentuk tabel, dan gambar. Untuk membandingkan antara dua nilai tengah maka di analisis dengan uji banding t-test menurut Steel dan Torrie (1993).

\section{Variabel Penelitian}

\section{Response Rate}

Perbandingan jumlah betina donor yang respon terhadap jumlah betina yang disuperovulasi. Donor dianggap memberikan respon bila corpus luteum (CL) yang dihasilkan > 1 dan dianggap tidak berespon apabila CL yang dihasilkan sama dengan satu

2. Jumlah CL pada ovarium kiri dan kanan:

Penghitungan jumlah CL pada ovarium kiri dan kanan, secara palpasi rectal dilakukan sebelum panen embrio.

\section{Total embrio dan ovum yang terkoleksi}

Jumlah embrio yang diperoleh, jumlah embrio yang layak transfer (A,
B, C), jumlah embrio yang tidak layak transfer (yang degenerasi dan jumlah oosit yang tidak terbuahi). Proposi embrio yang layak transfer yaitu perbandingan jumlah embrio layak transfer $(\mathrm{A}, \mathrm{B}, \mathrm{C})$ terhadap jumlah embrio dan oosit yang terkoleksi (A,B,C,Dg,Uf) dengan rumus :

PELT $=\frac{\text { embrio layak transfer }(A, B, C)}{\sum \text { embrio dan oosit }(A, B, C, D g, U f)} \times 100 \%$

\section{Cara pengumpulan data}

Evaluasi embrio berdasarkan kualitas dan berpedoman pada klasifikasi International Embryo Transfer Society (IETS) yang membagi kualitas embrio kedalam lima kelompok (grade) yaitu grade $\mathrm{A}, \mathrm{B}, \mathrm{C}, \mathrm{Dg}$ (degenerated) dan Uf (Unfertilized). Klasifikasi embrio tersebut tidak berbeda dengan evaluasi embrio berdasarkan klasifikasi IETS dan dinilai berdasarkan morfologi seperti bentuk, warna, densitas/kepadatan sitoplasma dan area yang mengalami degenerasi dapat dilihat pada Tabel 1. 
Tabel 1. Klasifikasi International Embrio Transfer Society (IETS) menurut Sato (1997)

\begin{tabular}{cll}
\hline Klasifikasi & Grade & \multicolumn{1}{c}{ Keterangan } \\
& & $>$ Embrio yang ideal, berbentuk bola \\
Exellent & $>$ Simetris dengan ukuran sel, \\
& $>$ Batas tepi jelas dan mulus, blastomer \\
& & kompak \\
& $>$ Warna dan tekstur yang seragam/sama \\
& $>$ Morfologi embrio baik \\
Good & $>$ Bentuk tidak beratuan \\
& $>$ Kerusakan blastomer 10- 20\% \\
& $>$ Kerusakan blastomer 20-3-\% \\
& $>$ Batas tepi tidak jelas \\
Fair & $>$ Blastomer kurang kompak \\
& $>$ Terbentuk vesikel-vesikel \\
& $\mathrm{C}$ & $>$ Bentuk tidak normal \\
& $>$ Blastomer terpisah (tertekan) \\
& $>$ Sel tergenerasi \\
\hline \multirow{2}{*}{ Poor } & $>$ Oosit tidak mengalami pembelahan \\
& & $>$ Badan kutub tidak jelas \\
\hline \multirow{2}{*}{ Unfertillized } & &
\end{tabular}

Sumber : Bố dan Mapletoft (2013)

\section{HASIL DAN PEMBAHASAN}

\section{Tingkat Respon sapi terhadap superovulasi (Respons Rate)}

Hasil pengamatan terhadap tingkat respons sapi donor terhadap superovulasi disajikan pada Tabel 2. Data pada Tabel 2 menunjukkan bahwa seluruh sapi donor yang disuperovulasikan sebanyak 50 ekor memberikan respons $100 \%$. Hal ini berarti bahwa seluruh sapi betina donor Limousin maupun Simmental yang disuperovulasikan dengan Folltropin ${ }^{\circledR}-\mathrm{V}$ dengan dosis $400 \mathrm{Mg}$ memberikan repons yang sama baik. Penggunaan Folltropin ${ }^{\circledR}-\mathrm{V}$ dengan dosis $400 \mathrm{Mg}$ pada bangsa sapi yang berbeda tidak memberikan respons yang berbeda.

Tabel 2. Respons sapi terhadap superovulasi

\begin{tabular}{lccc}
\hline $\begin{array}{c}\text { Bangsa sapi } \\
\text { donor }\end{array}$ & $\begin{array}{c}\sum \text { superovulasi } \\
\text { (ekor) }\end{array}$ & $\begin{array}{c}\sum \text { sapi donor yang respons } \\
\text { (ekor) }\end{array}$ & $\begin{array}{c}\text { Respons Rate } \\
(\%)\end{array}$ \\
\hline Limousin & 25 & 25 & 100 \\
Simmental & 25 & 25 & 100 \\
\hline
\end{tabular}


Tingkat respons superovulasi yang sama dan tinggi (100\%) dari sapi donor Limousin dan Simmental di BET Cipelang yang diinduksi dengan Folltropin ${ }^{\circledR}-\mathrm{V}$, diduga disebabkan superovulasi dilaksanakan pada saat yang tepat sehingga gonadotropin yang digunakan efektif merangsang perkembangan folikel sub ordinat menjadi folikel dominant dan selanjutnya menjadi folikel de Graaf, folikel yang siap diovulasikan. Perlakuan pemberian FSH eksogenous metode intarmuscular (IM) pada hari ke sembilan memberikan sensifitas yang tinggi, karena pada saat tersebut kondisi fisiologis ternak donor berada pada fase luteal dengan kondisi memiliki gelombang folikel. Setiadi et al. (2005), menyatakan bahwa aplikasi hormon gonadotropin pada saat muncul gelombang folikel dapat meningkatkan respons superovulasi jika dilakukan pada waktu gelombang folikel terjadi tanpa keberadaan folikel dominan. Hiraizumi et al. (2012). Dugaan lain yang menyebabkan tingkat respons yang sama dan tinggi dari sapi donor Limousin dan Simmental yaitu dosis FSH yang digunakan sama 400 mg, BCS yang yang hampir sama sekitar 2,5 - 3 dan perlakuan manajemen TE yang baik dimana jumlah pemakaian ternak sebagai donor hamya dua kali dalam setahun. Kanagawa et al. (1995) menyatakan bahwa tingkat respons yang tinggi sapi donor terhadap superovulasi dipengaruhi oleh beberapa faktor antara lain umur ternak donor, Body Condition Score (BCS), jumlah pemakaian sebagai donor, dosis FSH dan ada tidaknya gangguan reproduksi pada ternak tersebut. Suradi (2004) menyatakan bahwa sapi Simmental memberikan respons yang sama dengan sapi Limousin terhadap superovulasi yaitu sebesar $100 \%$.

\section{Jumlah CL yang dihasilkan ovarium kanan dan kiri sapi donor Limousin dan Simmental}

Pemeriksaan ada tidaknya CL pada ovarium kiri dan kanan sapi donor berlangsung pada hari ke tujuh setelah terlihat tanda-tanda estrus. Hasil perolehan jumlah CL pada ovarium kanan dan kiri sapi donor Limousin dan Simmental tersaji pada Tabel 2.

Hasil pengamatan menunjukkan angka rerata jumlah CL sapi donor Limousin untuk ovarium kiri dan kanan masing-masing $6,36 \pm 3,18$ dan $6,24 \pm$ 3,64 sedangkan sapi donor Simmental 8,48 $\pm 5,66$ dan $8,28 \pm 5,72$. Data hasil pengamatan ini menunjukkan bahwa ovarium bagian kiri dari sapi donor Limousin maupun sapi donor Simmental lebih banyak menghasilkan CL dibanding dengan ovarium kanan. Secara fisiologis, dapat dijelaskan bahwa hal ini dapat terjadi karena ovarium kiri dari sapi donor 
Tabel 3. Jumlah CL ovarium kanan dan kiri sapi donor Limousin dan Simmental

\begin{tabular}{|c|c|c|c|}
\hline Ovarium & Rerata & Sd & KK (\%) \\
\hline \multicolumn{4}{|c|}{ Limousin } \\
\hline Kanan & 6,24 & 3,64 & 58,33 \\
\hline Kiri & 6,36 & 3,18 & 94,68 \\
\hline \multicolumn{4}{|c|}{ Simmental } \\
\hline Kanan & 8,28 & 5,72 & 69,08 \\
\hline Kiri & 8,48 & 5,66 & 66,74 \\
\hline \multicolumn{4}{|c|}{ Rerata CL sapi donor Limousin dan Simmental } \\
\hline Limousin & 12,28 & 5.72 & 46.57 \\
\hline Simmental & $15.96 *$ & 5.32 & 33.33 \\
\hline
\end{tabular}

Limousin maupun Simmental lebih banyak memperoleh aliran darah dibanding ovarium kanan, sehingga menyebabkan aktivitas yang tinggi. Hasil penelitian ini sejalan dengan hasil penelitian dari Imron dan Supriatna (2016) yang melaporkan bahwa meskipun prosentase CL di ovarium kiri dan kanan sapi Limousin dan Simmental secara statistik tidak terdapat perbedaan yang nyata, namun penelitian dari Takdir et al. (2014), terdapat kecenderungan prosentase $\mathrm{CL}$ terbesar dihasilkan oleh ovarium kiri (65 dan 35) untuk Simmental dan Limousin (56 dan 44). Lebih jauh Takdir et al. (2014) telah melakukan penelitian juga pada ternak sapi Bali dan melaporkan bahwa aktivitas ovarium kiri sapi Bali lebih tinggi dibandingkan dengan ovarium kanan.

Rerata jumlah $\mathrm{Cl}$ hasil superovulasi sapi donor Limousin dan Simmental masing-masing 12,28 \pm 5,72 dan 15,96 \pm 5,32. Hasil statistik uji-t menunjukkan bahwa sapi donor Simmental yang diberikan folltropin ${ }^{\circledR}$ dosis 400 cc selama empat hari menunjukkan perbedaan. Sapi Simmental menunjukkan lebih tinggi $\mathrm{Cl}$ dibandingkan dengan sapi Limousin. Hasil ini juga menunjukkan bahwa bangsa ternak memberikan perbedaan yang sangat nyata pada taraf significan $1 \%(\mathrm{P}<0,01)$ dalam menghasilkan CL. Pada Tabel 3, jumlah CL kanan dan kiri sapi Simental dan Limousin menunjukkan hampir sama dengan yang dikemukakan oleh Prasetyo (2012) menyatakan bahwa pemberian FSH selama empat hari pada sapi donor Simmental cenderung menghasilkan rerata CL lebih banyak 8,3 $\pm 4,2$ (buah/ekor) dibanding dengan perlakuan pemberian FSH selama empat hari pada sapi donor Limousin 7,2 \pm 5,5 (buah/ekor).

Respons ovarium terhadap perlakuan superovulasi tergantung atau berkaitan erat dengan status perkembangan folikel pada saat perlakuan (Sato et al., 
2005). Respons lebih rendah yang terjadi pada sapi donor diduga karena pada waktu perlakuan bersamaan dengan adanya folikel dominan yang menghasilkan inhibin sehingga menekan pertumbuhan folikelfolikel subordinat (Martins et al., 2012).

\section{Kualitas Embrio sapi donor Limousin dan Simmental}

Rerata jumlah ovum yang terkoleksi layak trasfer (LT), embrio Degenerate (DG) dan Embrio (Uf) Unfertilized disajikan dalam Tabel 4. Layak tidaknya embrio hasil koleksi dari sapi donor yang ada di BET Cipelang sesuai dengan klasifikasi IETS (Gambar 6). Rerata jumlah embrio layak transfer (LT) pada sapi donor Limousin $10,12 \pm 5,12$ sedangkan sapi donor Simmental 13,8 $\pm 10,05$. Data diatas juga menunjukan bahwa sapi donor Simmental lebih banyak menghasilkan embrio yang tidak berkembang Dg $(3,28)$ dibandingkan dengan sapi Limousin 2.92 sedangkan embrio yang tidak fertil (Uf) sapi donor Simmental menghasilkan rerata 2,25 embrio per donor dan sapi Limousin 1,88 embrio per donor. Hasil uji-t menunjukan perbedaan yang tidak nyata $(\mathrm{P}>0,05)$, hal ini berarti sapi donor Simmental dan Limousin yang di superovulasi Folltropin $®-\mathrm{V}$ sama dalam menghasilkan embrio yang degenerasi (Dg). Berbeda hasilnya dengan perolehan embrio yang kategori Uf.

Hasil penelitian menunjukan bahwa sapi donor Simmental menghasilkan rerata embrio kategori Uf (embrio yang tidak terbuahi) 2,25 $\pm 1,88$ buah per donor, sedangkan sapi donor Limousin 1,88 \pm 1,26 buah per donor. Data ini menunjukan bahwa sapi donor Simmental mempunyai peluang lebih banyak menghasilkan embrio

Tabel 4. Kualitas embrio (LT, DG, UF) sapi donor Limousin dan Simmental

\begin{tabular}{llcc}
\hline Uraian & Rerata & Sd & KK\% \\
\hline Layak Trasfer & 10,12 & Limousin \\
Degenerate & 2,92 & 5,12 & 50,59 \\
Unfertilized & 1,88 & 1,94 & 66,43 \\
\hline & 1,26 & 67,02 \\
\hline Layak Trasfer & 13,8 & Simmental \\
Degenerate & 3,28 & 10,05 & 72,84 \\
Unfertilized & 2,25 & 2,26 & 68,90 \\
\hline
\end{tabular}


kualitas Uf dibanding dengan sapi donor Limousin. Hasil uji-t menunjukkan adanya perbedaan yang sangat nyata $(\mathrm{P}<0,01)$ antara sapi donor Simmental dan Limousin dalam menghasilkan embrio kategori Uf. Adriani et al. (2007) menyatakan bahwa adanya perbedaan dalam jumlah perolehan embrio kategori Uf dapat di sebabkan oleh beberapa faktor seperti teknik IB. ketrampilan inseminator kurang makan, defisiensi pakan, dan faktor interen dari hewan tersebut termasuk genetik, sedangkan Seidel dan Elsden (1989), menyatakan bahwa fertilisasi yang rendah dapat disebabkan oleh kualitas semen yang rendah, teknik serta waktu inseminator yang kurang tepat. Hafizuddin et al. (2012) Metode superovulasi dengan cara pemberian Folltropin ${ }^{\circledR}-\mathrm{V}$ pada hari ke tujuh mampu menstimulasi perkembangan folikel dan menghasilkan sedikit embrio yang kategori Uf pada sapi donor Limousin.

\section{KESIMPULAN}

Superovulasi dengan mengunakan Folltropin ${ }^{\circledR}-\mathrm{V}$ pada sapi Simmental dan Limousin di Balai Embrio Ternak Cipelang memberikan respon superovulasi yang sama, sedangkan untuk menghasilkan $\mathrm{Cl}$ dan embrio DG lebih banyak pada sapi Simmental dibandingkan dengan sapi Limousin. Untuk ovum kategori LT dan Uf, sapi donor Simmental berbeda sangat nyata lebih tinggi dibandingkan sapi Limousin.

\section{DAFTAR PUSTAKA}

Adriani, Depison, B. Rosadi, Y. Supriondo dan Isroli. 2007. Pengaruh superovulasi terhadap jumlah corpus luteum pada sapi Simbrah. J. Trop. Anim. Agri. 32 [3]. Hal: 207-212.

Bố, G.A. dan R.J. Mapletoft. 2013. Evaluation and classification of bovine embryos. Anim Repro 10 [3]: 344-348.

Fortune, J.E. 1994. Ovarian Follicular, growth and development in animals. J. Biol. Repr.50:225-232

Gordon. 2003. Perubahan ukuran folikel ovarium dan kualita soosit pada ovarium domba lokal pasca preservasi dengan waktu yang berbeda. J. Ilmu Ternak. Vol 16. No 1 .

Hafizuddin, T.N. Siregar, M. Akmal, J. Melia, Husnurrizal, dan T. Armansyah. 2012. Perbandingan intensitas berahi sapi aceh yang disinkronisasi dengan prostaglandin F2 alfa dan berahi alami. J. Ked. Hewan. 6(2):81-83.

Hiraizumi, S., H. Nishinomiya, T. Oikawa, N. Sakagami, F. Sano, O. Nishino, T. Kurahara, N. Nishimoto, O. Ishiyama, Y. Hasegawa, Y. Hashiyada. 2015. Superovulatory response in Japanese Black cows receiving a single subscutaneous porcine follicle-stimulating hormone treatment or six intramuscular treatments over three days. J. Theriogenology 83: 466-473. 
Imron, M. dan I. Supriatna. 2016. Respons superovulasi sapi peranakan ongole terhadap penyuntikan tunggal follicle stimulating hormon ke dalam ruang epidural. J. Vet. Vol 17. [1] Hal: 78-87

Kanagawa, H.I Shimamora dan N. Saito. 1995. Manual of Bovine Embryo Tarnsfer. Japan Livestock Technology Association, Toky

Martins, C.M., C.A. Rodrigues, L.M. Vieira, R.J. Mapletof, G.A. Bo, M.F. Sa Filho dan P.S. Baruselli. 2012. Holstein cows undergoing fixedtime artificial insemination. J. Theriogenology 78: 974-980.

Prasetyo, D. 2012 Tingkat Superovulasi Pada Beberapa Bangsa Sapi Dengan Sumber Follicle Stimulating Hormone (FSH) Yang Berbeda. Skripsi. Fakultas Peternakan IPB Bogor.

Sato, T., K. Nakada, Y. Uchiyama, Y. Kimura, N. Fujiwara, Y. Sato, M. Umeda, T. Furukawa. 2005. The Effect of Pretreatment with Different Doses of GnRH to Synchronize Follicular Wave on Superstimulation of Follicular Growth in Dairy Cattle. J Reprod and Dev 51(5): 573-578.

Setiadi, P.L., I. Supriatna dan A.Boediono. 2005. Follicle development after gonadotrophin treatment in garut sheep for laparoscopic ovum pick up, J. Agri Rur Dev in the tropic and subtropicks 83: 153-158.Seidel, G. E. dan R. P. Elsden. 1989. Embryo Transfer in Dairy Cattle. WD Hoard \& Sons, Colorado.

Suradi, 2004. Kualitas embrio hasil inseminasi buatan (IB) sapi Limousin dan Simmental dengan sapi Bali. Skripsi . Fakultas Peternakan, Institut Pertanian Bogor, Bogor.

Takdir, S., Fatmawati, A.S. Aku. 2014 Gambaran aktivitas ovarium sapi bali betina yang dipotong pada rumah pemotongan hewan (rph) kendari berdasarkan folikel dominan dan corpus luteum Jurusan Peternakan, Fakultas Pertanian, Universitas Haluoleo, Kendari

Toelihere, M.R. 1993. Fisiologi Reproduksi Ternak. Angkasa Bandung

Yamin, M., I. Rahayu dan R. Afnan. 2014. Tingka laku dan Kesejatraan Ternak (Pengamatan Tingka Laku). IPB Press, Bogor 